Osch, M. van, Dulmen, S. van, Vliet, L. van, Bensing, J.M. Specifying the effects of physician's communication on patients' outcomes: a randomised controlled trial. Patient Education and Counseling: 2017, 100(8), 1482-1489

\begin{tabular}{|l|l|}
$\begin{array}{l}\text { Postprint } \\
\text { Version }\end{array}$ & 1.0 \\
\hline Journal website & http://www.pec-iournal.com/article/S0738-3991(17)30138-6/abstract \\
\hline Pubmed link & $\underline{\text { https://www.ncbi.nlm.nih.gov/pubmed/28318845 }}$ \\
\hline DOI & $10.1016 /$ j.pec.2017.03.009
\end{tabular}

This is a NIVEL certified Post Print, more info at http://www.nivel.eu

\title{
Specifying the effects of physician's communication on patients' outcomes: A randomised controlled trial
}

\author{
MARA VAN OSCH ${ }^{\mathrm{A}}$, SANDRA VAN DULMEN ${ }^{\mathrm{A}, \mathrm{B}, \mathrm{C}, \text {, , LIESBETH VAN VLIET }}{ }^{\mathrm{A}}$, JOZIEN BENSING $^{\mathrm{A}, \mathrm{D}}$ \\ ${ }^{a}$ NIVEL (Netherlands institute for health services research), PO Box 1568, 3500 BN Utrecht, \\ The Netherlands \\ ${ }^{\mathrm{b}}$ Department of Primary and Community Care, Radboud University Medical Centre, PO Box \\ 9101, 6500 HB Nijmegen, The Netherlands \\ ${ }^{c}$ Faculty of Health Science, University College of Southeast Norway, PO Box 7053, NO- \\ 3007 Drammen, Norway \\ ${ }^{d}$ Department of Clinical and Health Psychology, Utrecht University, PO Box 80140, 3508 TC \\ Utrecht, The Netherlands
}

\section{HighLightS}

- Communication can influence analogue patient outcomes using a RCT videovignette design.

- Positive affect communication can influence outcomes such as anxiety, mood and satisfaction.

- Positive expectations can influence outcomes such as self-efficacy and outcome expectancy.

- The most positive effects were found when positive affect-oriented communication was combined with positive expectations.

- Continued medical training and research are needed to harness the placeboeffects of medical communication into practice.

\begin{abstract}
Objective: To experimentally test the effects of physician's affect-oriented communication and inducing expectations on outcomes in patients with menstrual pain.

Methods: Using a $2 \times 2 \mathrm{RCT}$ design, four videotaped simulated medical consultations were used, depicting a physician and a patient with menstrual pain. In the videos, two elements of physician's communication were manipulated: (1) affect-oriented communication (positive: warm, emphatic; versus negative: cold, formal), and (2) outcome expectation induction (positive versus uncertain). Participants (293 women with menstrual pain), acting as
\end{abstract}


Osch, M. van, Dulmen, S. van, Vliet, L. van, Bensing, J.M. Specifying the effects of physician's communication on patients' outcomes: a randomised controlled trial. Patient Education and Counseling: 2017, 100(8), 1482-1489

analogue patients, viewed one of the four videos. Pre- and post video participants' outcomes (anxiety, mood, self-efficacy, outcome expectations, and satisfaction) were assessed.

Results: Positive affect-oriented communication reduced anxiety $(p<0.001)$, negative mood $(p=0.001)$, and increased satisfaction $(p<0.001)$ compared to negative affect-oriented communication. Positive expectations increased feelings of self-efficacy $(p<0.001)$ and outcome expectancies $(p<0.001)$, compared to uncertain expectations, but did not reduce anxiety. The combination of positive affect-oriented communication and a positive expectation reduced anxiety $(p=0.02)$, increased outcome expectancies $(p=0.01)$ and satisfaction $(p=0.001)$.

Conclusion: Being empathic and inducing positive expectations have distinct and combined effects, demonstrating that both are needed to influence patients' outcomes for the best.

Practice implications: Continued medical training is needed to harness placeboeffects of medical communication into practice.

\section{INTRODUCTION}

Communication is one of the cornerstones of high quality medical care. The way physicians communicate with their patients elicits genuine effects on patient outcomes. These effects can be seen as placebo-effects [1]; [2]; [3]; [4] ; [5] which can be explained by psychological mechanisms, such as anxiety reduction and expectancy manipulation [6] ; [7]. Hence, physicians' affect-oriented communication and the induction of expectations are expected to produce placeboeffects along these two distinct pathways [1]; [2] ; [8].

First, positive affect-oriented communication, i.e. communicating in a warm, reassuring manner, being empathic, and addressing patients' emotions, is targeted at establishing a good physician-patient relationship. It can reduce patients' anxiety and distress, and provide them with a feeling of support and caring [1]; [2]; [8] ; [9] while also improving outcomes such as satisfaction and adherence [10]; [11] ; [12]. Contrary, the lack of empathy or negative affect-oriented communication is associated with adverse effects, including an increase in patients' anger and frustration [13], deteriorated recall [14], and even malpractice claims [15].

Second, raising expectations about one's prognosis or treatment outcome can shape patients' beliefs about the controllability of the treatment (i.e. outcome expectancy) and alter their beliefs about one's ability to cope with the disease and its treatment (i.e. self-efficacy) [16]. The verbal suggestion that a drug has powerful effects creates placebo effects, such as decreased pain, anxiety, and opioid intake [17]; [18]; [19]; [20] ; [21]. Framing expectations is important for the direction of the effect [22] ; [23], and patients' expectations regarding painful or adverse effects are important determinants of unwanted effects [24]; [25].

While these distinct communication elements can influence patients' outcomes, few studies have assessed the relative and combined contribution of affect-oriented communication and inducing expectations. In their study on patients with bursitis or tendonitis, Berk et al., for example, showed that a positive milieu in which acupuncture was delivered contributed to the effect resulting from (the suggestion of) 
Osch, M. van, Dulmen, S. van, Vliet, L. van, Bensing, J.M. Specifying the effects of physician's communication on patients' outcomes: a randomised controlled trial. Patient Education and Counseling: 2017, 100(8), 1482-1489

being treated [26]. Gryll and Katah [27] found that enthusiastic messages of drug effects lead, among others, to significant lower ratings of pain. More recently, Kaptchuk et al. showed the added value of the doctor-patient relationship augmented with warmth, attention, and confidence on symptom severity in irritable bowel syndrome being treated by acupuncture [28].

In a previous (pilot) study [29], we asked women with a history of period pain to role-play a consultation with a trained physician, who displayed either a high or low affective attitude and raised high or low expectations about the effect of prescribed treatment, and to subsequently view their role-played interaction on video. This study showed that both types of communication had positive, but distinct effect on patients' outcomes [29]. However, whether the same results would be found in a larger study and with a more rigorous methodology is unclear. The aim of the present study therefore is to extend our previous study and experimentally manipulate and examine the relative and combined effects of physician's affect-oriented communication and the induction of expectations. Videotaped medical consultations were used depicting a physician and a patient discussing menstrual pain. Menstrual pain was chosen as (menstrual) pain is credited with being subject to placebo-effects [18]; [19]; [20]; [30] and is a frequently reported symptom [31]. It is expected that: (1) positive affect-oriented communication by the physician decreases patients' anxiety and negative mood, and increases positive mood and satisfaction, compared to negative affect-oriented communication, (2) the communication of positive outcome expectation by the physician decreases patients' anxiety and negative mood, and enhances outcome expectancy and self-efficacy compared to an uncertain expectation (3) there is an interaction between affect-oriented communication and expectations: positive affect-oriented communication increases the effect of expectations, while negative affect-oriented communication reduces these effects.

\section{METHODS}

\subsection{Experimental videos}

In a $2 \times 2$ RCT design, videotaped simulated consultations produced as part of the previous study were used [29]. These videos varied from one another in one element of physician's affect-oriented communication and one element of inducing outcome expectations: (1) affect (+: positive; warm, empathic; versus - : negative; cold, formal), and (2) expectation (+: positive outcome; versus-: uncertain outcome). Two independent coders rated GP's communication with the Roter method of interaction process analysis (RIAS) [32] to assess whether the videos truly differed in communication. Four videos of the 30 videos were selected that showed a maximum heterogeneity in the two manipulated communication elements.

The videos depicted medical consultations in which a volunteer patient presented real menstrual pain disabling her daily activities to an actual, female GP. The volunteer patient received a script about the presented problem, and the GP was trained in the different communication styles. The GP asked about patient's menstrual pain and complaints, gave recommendations about medication (i.e. the use of non-steroidal anti-inflammatory drugs; NSAIDs) and further possibilities to prevent pain. Due to the scripted role-playing approach, there was a high control over the GP's communication.

The positive affect-oriented videos showed a warm and friendly GP, opening in an inviting manner, showing empathy ("This must be very difficult for you", and "I 
Osch, M. van, Dulmen, S. van, Vliet, L. van, Bensing, J.M. Specifying the effects of physician's communication on patients' outcomes: a randomised controlled trial. Patient Education and Counseling: 2017, 100(8), 1482-1489

noticed that this problem put quite a strain on you"), addressing the psychosocial context of the patient, and directing eye contact and body posture toward the patient. In the negative affect-oriented videos the GP acted rather cold and formal: the GP made no empathic statements, did not further explore, or was ignorant to, patients' expressions of emotions, showed to be easily distracted, a diverted body posture, and only briefly looked in the direction of the patient, while frequently looking at paperwork [29].

In addition, all videos included either a positive or uncertain outcome expectation. In the positive expectation videos, the GP praised the effectiveness of NSAIDs in reducing menstrual pain ("This medicine works for a lot of women", and "I'm sure that you will benefit from it too"). In the uncertain expectation videos the GP also mentioned the use of NSAIDs, but commented that its effect on menstrual pain is uncertain ("I'm not sure whether this will help you much") [29]. NSAIDs are used to reduce menstrual pain or cramps, and the GP prescribes a maximum daily dosage of $2400 \mathrm{mg}$.

Participants in our study were randomly assigned to view and judge one of the four videos. Group 1 viewed the +affective/+expectation video (length: $9.98 \mathrm{~min}$ ); Group 2 the -affective/-expectation video (length: $8.34 \mathrm{~min}$ ); Group 3 the +affective/-expectation video (length: $7.35 \mathrm{~min}$ ); and Group 4 the -affective/+expectation video (length: $7.22 \mathrm{~min}$ ).

\subsection{Study sample}

Participants were recruited by information leaflets at various locations i.e. waiting rooms at health centres, pharmacists, local supermarkets, gyms, (university) libraries, community centres, via calls in women's magazines and newspapers, snowballing procedures, and via Internet, forum boards, and social media. Inclusion criteria were being female, having a menstrual cycle and suffering from menstrual pain at least once in the last six months, aged 18-45 years, and having sufficient command of Dutch. Data were collected between February 2013 and June 2013.

Participants took part as analogue patients (APs) and were instructed to identify with the video-patient, while viewing and judging the consultation. More specifically, they were instructed as follows: "You will be watching a video-taped simulated consultation. While watching the video, place yourself in the position of the videopatient while imagining how you would feel if you were in this consultation". APs have been used in several studies reporting representative [12]; [29] ; [33] and valid measures [34] ; [35] of clinical patients. To optimise validity, studies recommended matching APs and clinical patients on characteristics such as age and gender. Therefore, we only included women in a reproductive age (between 18 and 45 years of age), who reported to have a menstrual cycle and suffering from menstrual pain to maximise empathic involvement between APs and the video-patient and to minimise confounding gender effects. We estimated a priori, based on the effect size of the State Trait Anxiety Inventory (STAI-S) [36] from a study using similar experimental methodologies, [37] that a sample size of 309 women would attain $80 \%$ power for determining two main effects and one interaction effect at $p<0.05$.

\subsection{Study variables}

\subsubsection{Background characteristics (baseline)}


Osch, M. van, Dulmen, S. van, Vliet, L. van, Bensing, J.M. Specifying the effects of physician's communication on patients' outcomes: a randomised controlled trial. Patient Education and Counseling: 2017, 100(8), 1482-1489

Participants' age, nationality, education, occupation, and marital status were assessed. Additionally, self-reported menstrual pain (1 item, visual analogue scale (VAS) measuring pain intensity range 0-100) and functional health status (using the 7-item COOP-WONCA [38]) were assessed, as these may influence participants' communication preferences and needs.

\subsubsection{Anxiety (pre- and post-video)}

Participants' state anxiety was measured using the shortened State Trait Anxiety Inventory (STAI-S) [36]; 10 items, scale ranging from 1: not at all to 4: very much e.g. "I am tense", $\alpha=0.82$ (pre); $\alpha=0.94$ (post)).

\subsubsection{Mood (pre- and post-video)}

Mood was measured using the Positive and Negative Affect Schedule (PANAS) [39]; 20-items, scale ranging from 1: not at all to 5: very much, e.g. "I am exited" or "I am upset"). For the positive mood items, Cronbach's alphas were 0.77 (pre) and 0.86 (post), for the negative mood scale 0.74 (pre) and 0.82 (post).

\subsubsection{Self-efficacy and outcome expectancies (pain coping) (pre- and post-video)}

Coping with menstrual pain was assessed using the Revised Illness Perception Questionnaire (IPQ-R) [40]; 38-items ranging from 1: strongly disagree to 5: strongly agree, $\alpha=0.87$ (pre); $\alpha=0.94$ (post)). Only the subscales personal control and treatment control were analysed. Personal control measures self-efficacy beliefs, i.e. the belief about one's ability to influence menstrual pain by carrying out the actions necessary for successful management and coping (6-items, e.g. "I have the power to influence my menstrual pain"). Treatment control measures outcome expectancies; i.e. the belief that a treatment will have an effect on menstrual pain (5items, e.g. "The negative effects of my menstrual pain can be prevented by my treatment"). Higher scores represent more positive beliefs about the ability to cope with their menstrual pain. In the Results section, the terms self-efficacy beliefs and outcome expectancies will be used.

\subsubsection{Satisfaction (post-video)}

Participants' satisfaction with the consultation was assessed (1-item, range from 1: low to 10: high, "Please indicate how satisfied you were with this consultation").

\subsubsection{Manipulation check (post-video)}

The success of the manipulation was determined using the Consultation and Relational Empathy Measure (CARE) [41]; 10 items, range 1: poor-5: excellent, e.g. "How was the doctor at showing care and compassion", $\alpha=0.95)$. Furthermore, we assessed on a 1-10 scale (low-high) participants' perceived realism of the videoconsultation (1-item, "Please indicate how realistic the video was in your opinion") and their ability to identify with the video-patient (1-item, "How well did you identify yourself with the patient in the video?"). A score of $\geq 6$ was considered sufficient.

\subsection{Procedure}

This study was approved by the Medical Ethical Committee of Utrecht University (Reference 08-292/O, December 2012), the Netherlands. All participants received by 
Osch, M. van, Dulmen, S. van, Vliet, L. van, Bensing, J.M. Specifying the effects of physician's communication on patients' outcomes: a randomised controlled trial. Patient Education and Counseling: 2017, 100(8), 1482-1489

postal mail an information-letter about the study and an informed consent form. The content disclosure omitted specific study aims. Upon receiving consent, a short telephone screening was performed checking the inclusion criteria, and announcing the sending of the background characteristics questionnaire. Subsequently, participants were randomised via altering enrolment to one of the four conditions. Upon receipt of the completed questionnaire, an appointment by telephone or email was planned for the experiment. Participants participated in groups at our research institute, with a maximum number of 20 participants per group. It was emphasised that, although situated in a group, it was necessary to complete the questionnaires individually and in silence. Pre- and post- video-viewing the questionnaires were completed (ca. $30 \mathrm{~min}$ in total). Finally, participants were debriefed and received a gift voucher of $€ 20$.

\subsection{Statistical analysis}

Data analyses were performed using STATA 12.0, at $\alpha=0.05$ (two-tailed). First, frequencies and means were calculated for background and outcome variables. Analyses of variance (ANOVA) and $\chi^{2}$ tests were performed to compare background characteristics between groups. Second, as background characteristics can influence communication preferences, it was checked whether these showed an effect on the outcome variables using stepwise regression analysis. If so, we controlled for these variables in the subsequent analyses. Participants' pre-video outcomes were also controlled for. Third, paired sample $t$-tests were performed to determine within group differences (pre and post-video measures). Fourth, contrast tests with Bonferroni adjustments were performed to determine the differences between groups. Fifth, multiple regression analyses were performed to determine the distinct effect of affect and expectations. Outcomes were centred ( $z$-scores) to prevent multicollinearity. Affect (positive versus negative) and Expectations (positive versus uncertain) were dummy coded.

\subsubsection{Missing data}

A total of 387 participants signed up of which 323 were eligible and willing to participate. Twenty-seven participants failed to meet the appointment, and three participants were excluded from analyses due to missing background characteristics and pre-questionnaires at baseline. Fig. 1 provides a flow chart.

\section{[FIGURE. 1]}

\section{RESULTS}

\subsection{Background characteristics and control variables}

A total of 293 women participated. Background characteristics are summarised in Table 1. No differences were found between groups, indicating equality of groups. Age and functional health status were significantly $(p<0.05)$ correlated with the post-video measures and were taken as control variables, next to participants' prevideo measures. 
Osch, M. van, Dulmen, S. van, Vliet, L. van, Bensing, J.M. Specifying the effects of physician's communication on patients' outcomes: a randomised controlled trial. Patient Education and Counseling: 2017, 100(8), 1482-1489

\section{[Table 1]}

\subsection{Manipulation check}

The groups differed in perceived empathy, $F(3292)=241.16, p<0.0001$. The two positive affect-oriented videos were perceived as being more empathic (group 1: $M=35.79, \mathrm{SD}=7.18$; group $3: M=28.39, \mathrm{SD}=6.99$ ) as scores were significantly $(p<0.0001)$ higher than participants' perceptions of the cold and formal videos (group 2: $M=14.02, \mathrm{SD}=3.77$; group 4: $M=15.51, \mathrm{SD}=4.19$ ).

Furthermore, all participants indicated being able to identify with the video-patient ( $M=7.90, \mathrm{SD}=1.27$, no differences between conditions $)$, and perceived the video as realistic $(M=7.11, \mathrm{SD}=1.54, F(3,292)=5.67, p<0.001)$. Whilst all videos were rated as realistic, the positive affect-oriented videos were perceived as more realistic (group 1: $M=7.45, \mathrm{SD}=1.44$; group 3: $M=7.47, \mathrm{SD}=1.35$ ) compared to the negative affect-oriented videos (group 2: $M=6.83, \mathrm{SD}=1.54$; group 4: $M=6.65$, $\mathrm{SD}=1.69)$. Group 4 differed significantly from group $1(p=0.010)$ and group 3 $(p=0.007)$.

\subsection{Pre-post video differences within groups}

Table 2 presents participants' pre and post-video measures. Results showed the most favourable effects for group 1 (+affect/+expectation), while group 2 (-affect/-expectation) showed the least favourable effects. For group 1 postmeasured anxiety and mood did not change, but increased self-efficacy beliefs and outcome expectancies were reported. Contrast tests showed that group 2 (-affect/-expectation) reported feeling more anxious $(t=8.35, p<0.0001)$ and having more negative mood $(t=3.89, p=0.001)$, while self-efficacy beliefs $(t=-9.12, p<0.0001)$; outcome expectancies $(t=-11.56, p<.0001)$ and satisfaction $(t=-14.07, p<0.0001)$ were lowered as compared to group 1 . No effects were found for participants' positive mood.

\section{[TABLE 2]}

\subsection{Distinct and combined effects of affect and expectation}

Affect (positive versus negative) and Expectations (positive versus uncertain) were dummy coded to specify the distinct and combined effect of each type of communication. The effects are summarised in Table 3. Positive affect-oriented communication reduced participants' anxiety $(\beta=-0.25, t=-3.66, p<0.001)$ and negative $\operatorname{mood}(\beta=-0.23, t=-3.38, p=0.001)$, and increased satisfaction $(\beta=0.49$, $t=7.79, p<0.001)$ relative to negative affect-oriented communication. GP's raising of a positive outcome increased participants' self-efficacy beliefs $(\beta=0.40, t=5.59$, $p<0.001)$ and outcome expectancies $(\beta=0.44, t=6.51, p<0.001)$ relative to an uncertain outcome, but did not influence participants' anxiety. The combination of both positive affect-oriented communication and a positive expectation reduced participants' anxiety $(\beta=-0.21, t=-2.45, p=0.02)$, increased their outcome expectancies $(\beta=0.20, t=2.47, p=0.01)$ and satisfaction $(\beta=0.24, t=3.23$, $p=0.001)$, but did not significantly influence their self-efficacy beliefs $(\beta=0.12$, $t=1.36, \mathrm{~ns})$. 
Osch, M. van, Dulmen, S. van, Vliet, L. van, Bensing, J.M. Specifying the effects of physician's communication on patients' outcomes: a randomised controlled trial. Patient Education and Counseling: 2017, 100(8), 1482-1489

\section{[TABLE 3]}

\section{DISCUSSION AND CONCLUSION}

\subsection{Discussion}

In this experimental study, the effects of physician's affect-oriented communication and the induction of expectations were tested. Our results showed that these communication elements can produce genuine distinct and combined effects: (a combination of) positive affect-oriented communication and physician's verbalisation of a positive treatment outcome can reduce participants' anxiety and negative feelings, and increase feelings of self-efficacy and outcome expectancies, and satisfaction.

These results add to the emerging literature on the causal and strong effects of specific communication elements on patient outcomes. While the positive placeboeffects of affect-oriented communication [2]; [12]; [29]; [37] ; [42] and positive expectations [17]; [18]; [21]; [43] ; [44] have been previously shown, this study demonstrated that both communication elements are necessary to improve patients' outcomes for the best, like only a few studies showed before (e.g. [26]; [27] ; [28]). A positive expectation only reduced participants' anxiety when communicated in a warm, empathic manner. This means that physician's empathy is of utmost importance for patients and must be considered as indispensable and of therapeutic value for health care [45]; [46] ; [47]. On the other hand, empathy only influences outcome expectations when clinicians raise positive expectations. This means that a (realistic) positive suggestion of a treatment outcome should be harnessed in clinical care, given that this verbalisation is embedded in an affective physician-patient interaction [1]; [3]; [5].

At the same time, our results illustrate that communication is a double-edged sword that can both heal and harm. Negative affect-oriented communication and uncertain outcome expectations, influenced patients' outcomes in a negative way. Increased anxiety and negative mood were reported, together with participants' reduced feelings of self-efficacy and outcome expectations. In a recent systematic review we indeed showed that the induction of negative expectations can influence clinical patients' pain [44]. The physician-patient relationship and interaction may simulate effects of an active treatment as emotion regulation processes are activated, and emotional activation is part of one's responding to pain [30]; [48] ; [49]. When taking this further, one could argue that physician's words can have the same effects on pain as drugs [24]; [30]; [50].

\subsubsection{Strengths, limitations and further research}

The strength of this study is its experimental design, in which the distinct (and combined) effects of physician's affect and expectations could be specified, which thus far hardly has been investigated. The experimental approach using analogue patients was suitable to overcome methodological, practical and ethical constraints, and to test the effects of the communication elements among a larger sample size and using a stronger methodology (patients randomly watched one video instead of their own videotaped encounter) than our previous study [29].

Nevertheless, the present study has limitations. Although analogue patients are valid proxies in medical communication research [34]; [35] and recommendations were followed to maximise concordance between participant and the video-patient (i.e. by 
Osch, M. van, Dulmen, S. van, Vliet, L. van, Bensing, J.M. Specifying the effects of physician's communication on patients' outcomes: a randomised controlled trial. Patient Education and Counseling: 2017, 100(8), 1482-1489

only including participants having menstrual pain), the inclusion of healthy women restricts generalisability. Next, gender differences are known to influence medical communication [51]; [52]. Since the GP in our video was also female, findings may be different with a male GP, or when men are taking part in a visit with a female or male GP. Second, our sample consisted of highly educated women and the majority of them being of Dutch nationality. High education is related with more expressive, actively communicating patients [53].

Another limitation concerns the fact that we have not assessed participants' prior use and experiences with NSAIDs (or other medication) to prevent menstrual pain. Prior experiences of a therapeutic outcome play an important role in patients' expectations of future responses [5] ; [48], and therefore could influence the (magnitude of the) effect of physician's communication. This remains an area for further research when exploring the clinical implications of inducing expectations.

Furthermore, our study focused on participants' immediate and subjective outcomes as those outcomes are related to the perception of one's medical condition [54] and therefore may contribute to clinical symptom relief. Yet, the immediate effects of communication remain to be investigated in respect to more distal outcomes like patients' medication adherence, recovery and healthcare utilisation to determine long-term effects.

\subsection{Conclusion}

In conclusion, our study demonstrated that physicians' positive affect-oriented communication and a positive expectation can produce genuine effects on patients' anxiety, mood, self-efficacy and outcome expectancies, and satisfaction. An affective physician-patient interaction characterised by a warm, empathic physician whom addresses patients' feelings, combined with a positive, truthful outcome expectation, seems to benefit patients the most.

\subsection{Practice implications}

As empathy and positive expectations are capable of influencing patients' outcomes, the question rises how these communication elements can best be embedded in clinical care. When looking at the induction of positive expectations, it is of course inappropriate to instil false hopes or provide untruthful medical information. First, patients are entitled to be fully informed about drug regimen and medical procedures (Medical Treatment Act, 1995), which include discussing risks, harms and medical uncertainties. Second, the wide variety of patients should be taken into account whereby medical information, advice and care have to be tailored to the individual person to provide optimal care. Severity, duration, disease history and prognosis of the patient's condition should be taken into account when inducing outcome expectations. Indeed, a balance must exist between communicating important clinical information while attempting to minimise negative effects [25]. Third, the induction of a positive outcome expectation has to be in line with physician's confidence in the expected effects on patient outcomes. With our findings, we want to advocate that physician's communication can elicit beneficial effects on patient outcomes, by choosing the right wording and positive framing when dealing with treatment information alongside of establishing and providing a trustful relationship. By providing a positive and truthful disclosure of the expected benefits of (drug) therapy, patients' expectancies can be raised which may support patients to adjust to 
Osch, M. van, Dulmen, S. van, Vliet, L. van, Bensing, J.M. Specifying the effects of physician's communication on patients' outcomes: a randomised controlled trial. Patient Education and Counseling: 2017, 100(8), 1482-1489

their medical condition and alter their health behaviour. More research is needed to establish how this can best be done in clinical care.

Moreover, while showing an empathic attitude might in essence be beneficial and does not raise any ethical concerns, it is not always used to its full potential in clinical care. Notably, in recent years there is a notion of empathy decline in medical education, training, and clinical practice [55] ; [56]. Moreover, patients' emotions or hints of (un)expressed emotions are often not adequately addressed [57] ; [58]. To respond to this worrisome tendency, medical communication training and interventions are essential and, above all, proven to be effective [59] ; [60]. Training should focus on both the verbal and non-verbal aspects of affective communication, and provide physicians with the skills and tools how to deal with, the often protocolised medical care and its focus on time efficiency and clinical productivity. It is important that both research and clinical care remain focused on practicing an affective physician-patient relationship.

\section{FUNDING}

This work was supported by the Spinoza Price awarded to Prof. Jozien Bensing, by the Dutch Research Council (NWO). NWO was not involved in the research process.

\section{CONFLICT OF INTEREST STATEMENT}

None.

\section{DETAILS OF ETHICS APPROVAL}

Ethics approval was obtained from the Medical Ethical Committee of Utrecht University (Reference 08-292/O, December 2012), the Netherlands. The trial is registered with the Dutch Trial registration: trialregister.nl, identifier NRT-3922.

\section{ACKNOWLEDGEMENTS}

We would like to thank all the participants in the study. We would also like to thank Peter Spreeuwenberg for his statistical advice.

\section{REFERENCES}

[1] J.M. Bensing, W. Verheul, The silent healer: the role of communication in placebo effects, Patient Educ. Couns. 80 (2010) 293-299.

[2] Z.D. Blasi, E. Harkness, E. Ernst, A. Georgiou, J. Kleijnen, Influence of context effects on health outcomes: a systematic review, Lancet 357 (2001) 757-762.

[3] H. Brody, F.G. Miller, Lessons from recent research about the placebo effect-from art to science, J Amer Med Assoc 306 (2011) 2612-2613.

[4] S.J. Griffin, A.-L. Kinmonth, M.W. Veltman, S. Gillard, J. Grant, M. Stewart, Effect on health-related outcomes of interventions to alter the interaction between patients and practitioners: a systematic review of trials, Ann. Fam. Med. 2 (2004) 595-608.

[5] D.G. Finniss, T.J. Kaptchuk, F. Miller, F. Benedetti, Biological, clinical, and ethical advances of placebo effects, Lancet 375 (2010) 686-695.

[6] F. Benedetti, Mechanisms of placebo and placebo-related effects across diseases and treatments, Annu. Rev. Pharmacol. Toxicol. 48 (2008) 33-60.

[7] D.D. Price, D.G. Finniss, F. Benedetti, A comprehensive review of the placebo effect: recent advances and current thought, Annu. Rev. Psychol. 59 (2008) 565-590.

[8] A.M. van Dulmen, J.M. Bensing, Health promoting effects of the physician-patient encounter, Psychol. Health Med. 7 (2002) 289-300. 
Osch, M. van, Dulmen, S. van, Vliet, L. van, Bensing, J.M. Specifying the effects of physician's communication on patients' outcomes: a randomised controlled trial. Patient Education and Counseling: 2017, 100(8), 1482-1489

[9] R.L. Street Jr., G. Makoul, N.K. Arora, R.M. Epstein, How does communication heal? Pathways linking clinician-patient communication to health outcomes, Patient Educ. Couns. 74 (2009) 295-301.

[10] K.B.H. Zolnierek, M.R. DiMatteo, Physician communication and patient adherence to treatment: a meta-analysis, Med. Care 47 (2009) 826-834.

[11] K.B. Haskard, M.R. DiMatteo, J. Heritage, Affective and instrumental communication in primary care interactions: predicting the satisfaction of nursing staff and patients, J. Health Commun. 24 (2009) 21-32.

[12] M. van Osch, M. Sep, L.M. van Vliet, S. van Dulmen, J.M. Bensing, Reducing patients' anxiety and uncertainty, and improving recall in bad news consultations, Health Psychol. 33 (2014) 1382-1390.

[13] K.L. Vangronsveld, S.J. Linton, The effect of validating and invalidating communication on satisfaction, pain and affect in nurses suffering from low back pain during a semistructured interview, Eur. J. Pain 16 (2012) 239-246.

[14] J. Jansen, J.C. van Weert, J. de Groot, S. van Dulmen, T.J. Heeren, J.M. Bensing, Emotional and informational patient cues: the impact of nurses' responses on recall, Patient Educ. Couns. 79 (2010) 218-224.

[15] N. Ambady, D. LaPlante, T. Nguyen, R. Rosenthal, N. Chaumeton, W. Levinson, Surgeons' tone of voice: a clue to malpractice history, Surgery 132 (2002) 5-9.

[16] R. Crow, H. Gage, S. Hampson, J. Hart, A. Kimber, H. Thomas, The role of expectancies in the placebo effect and their use in the delivery of health care: a systematic review, Health Technol. Assess. Rev. 3 (1999) 3.

[17] F. Benedetti, G. Maggi, L. Lopiano, M. Lanotte, I. Rainero, S. Vighetti, A. Pollo, Open versus hidden medical treatments: the patient's knowledge about a therapy affects the therapy outcome, Prev. Treat. 6 (2003) 1 a.

[18] L. Colloca, L. Lopiano, M. Lanotte, F. Benedetti, Overt versus covert treatment for pain, anxiety, and Parkinson's disease, Lancet Neurol. 3 (2004) 679-684.

[19] A. Pollo, M. Amanzio, A. Arslanian, C. Casadio, G. Maggi, F. Bendedetti, Response expectancies in placebo analgesia and their clinical relevance, Pain 93 (2001) 77-84.

[20] L. Vase, M.E. Robinson, G.N. Verne, D.D. Price, The contributions of suggestion, desire, and expectation to placebo effects in irritable bowel syndrome patients: an empirical investigation, Pain 105 (2003) 17-25.

[21] M.E. Suarez-Almazor, C. Looney, Y. Liu, V. Cox, K. Pietz, D.M. Marcus, R.L. Street Jr., A randomized controlled trial of acupuncture for osteoarthritis of the knee: effects of patient-provider communication, Arthritis Care Res. 62 (2010) 1229-1236.

[22] J. Dutt-Gupta, T. Bown, A. Cyna, Effect of communication on pain during intravenous cannulation: a randomized controlled trial, Br. J. Anaesth. 99 (2007) 871-875.

[23] D. Varelmann, C. Pancaro, E.C. Cappiello, W.R. Camann, Nocebo-induced hyperalgesia during local anesthetic injection, Anesth. Analg. 110 (2010) 868- 870.

[24] Placebo Competence Team, U. Bingel, Avoiding nocebo effects to optimize treatment outcome, J Amer Med Assoc 312 (2014) 693-694.

[25] L. Colloca, D. Finniss, Nocebo effects, patient-clinician communication, and therapeutic outcomes, J Amer Med Assoc 307 (2012) 567-568.

[26] S.N. Berk, M.E. Moore, J.H. Resnic, Psychosocial factors as mediators of acupuncture therapy, J. Consult. Clin. Psychol. 45 (1977) 612-619.

[27] S.L. Gryll, M. Katah, Situational factors contributing to the placebo effect, Psychopharmacology 57 (1978) 253-261.

[28] T.J. Kaptchuk, J.M. Kelley, L.A. Conboy, R.B. Davis, C.E. Kerr, E.E. Jacobson, I. Kirsch, R.N. Schyner, B.H. Nam, L.T. Nguyen, M. Park, A.L. Rivers, C. McManus, E. Kokkotou, D.A. Drossman, P. Goldman, A.J. Lembo, Components of placebo effect: randomised controlled trial in patients with irritable bowel syndrome, Brit. Med. J. 336 (2008) 999-1003.

[29] W. Verheul, A. Sanders, J. Bensing, The effects of physicians' affect-oriented communication style and raising expectations on analogue patients' anxiety, affect and expectancies, Patient Educ. Couns. 80 (2010) 300-306.

[30] F. Benedetti, How the doctor's words affect the patient's brain, Eval. Health Prof. 25 (2002) 369-386. 
Osch, M. van, Dulmen, S. van, Vliet, L. van, Bensing, J.M. Specifying the effects of physician's communication on patients' outcomes: a randomised controlled trial. Patient Education and Counseling: 2017, 100(8), 1482-1489

[31] A. Polat, H. Celik, B. Gurates, D. Kaya, M. Nalbant, E. Kavak, F. Hanay, Prevalence of primary dysmenorrhea in young adult female university students, Arch. Gynecol. Obstet. 279 (2009) 527-532.

[32] D. Roter, S. Larson, The roter interaction analysis system (RIAS): utility and flexibility for analysis of medical interactions, Patient Educ. Couns. 46 (2002) 243-251.

[33] M.S. Mast, J.A. Hall, C. Köckner, E. Choi, Physician gender affects how physician nonverbal behavior is related to patient satisfaction, Med. Care 46 (2008) 1212-1218.

[34] D. Blanch-Hartigan, J.A. Hall, E. Krupat, J.T. Irish, Can naive viewers put themselves in the patients' shoes?: reliability and validity of the analogue patient methodology, Med. Care 51 (2013) e16-e21.

[35] L.M. van Vliet, E. van der Wall, A. Albada, P.M. Spreeuwenberg, W. Verheul, J.M. Bensing, The validity of using analogue patients in practitioner-patient communication research: systematic review and meta-analysis, J. Gen. Intern. Med. 27 (2012) 1528-1543.

[36] H. Van der Ploeg, Validity of the Zelf-Beoordelings-Vragenlijst (A Dutch version of the Spielberger state-trait anxiety inventory), Ned. Tijdschr. Psychol. 35 (1980) 243-249.

[37] L.A. Fogarty, B.A. Curbow, J.R. Wingard, K. McDonnell, M.R. Somerfield, Can 40 seconds of compassion reduce patient anxiety? J. Clin. Oncol. 17 (1999) 371.

[38] C. Van Weel, Functional status in primary care: COOP/WONCA charts, Disabil. Rehabil. 15 (1993) 96-101.

[39] D. Watson, L.A. Clark, A. Tellegen, Development and validation of brief measures of positive and negative affect: the PANAS scales, J. Pers. Soc. Pyschol. 54 (1988) 10631070.

[40] R. Moss-Morris, J. Weinman, K. Petrie, R. Horne, L. Cameron, D. Buick, The revised illness perception questionnaire (IPQ-R), Psychol. Health 17 (2002) 1- 16.

[41] S.W. Mercer, M. Maxwell, D. Heaney, G.C. Watt, The consultation and relational empathy (CARE) measure: development and preliminary validation and reliability of an empathy-based consultation process measure, Fam. Pract. 21 (2004) 699-705.

[42] L.M. van Vliet, E. van der Wall, N.M. Plum, J.M. Bensing, Explicit prognostic information and reassurance about nonabandonment when entering palliative breast cancer care: findings from a scripted video-vignette study, J. Clin. Oncol. 31 (2013) 3242-3249.

[43] T. Fassaert, S. Van Dulmen, F. Schellevis, L. Van der Jagt, J. Bensing, Raising positive expectations helps patients with minor ailments: a cross-sectional study, BMC Fam. Pract. 9 (2008) 38.

[44] P. Mistiaen, M. van Osch, L. van Vliet, J. Howick, F.L. Bishop, Z. Di Blasi, J. Bensing, S. van Dulmen, The effect of patient-practitioner communication on pain: a systematic review, Eur. J. Pain 20 (2016) 675-688.

[45] J. Bensing, M. Rimondini, A. Visser, What patients want, Patient Educ. Couns. 90 (2013) 287-290.

[46] H. de Haes, J. Bensing, Endpoints in medical communication research, proposing a framework of functions and outcomes, Patient Educ. Couns. 74 (2009) 287-294.

[47] F. Derksen, J. Bensing, A. Lagro-Janssen, Effectiveness of empathy in general practice: a systematic review, Br. J. Gen. Pract. 63 (2013) e76-e84.

[48] F. Benedetti, M. Amanzio, The placebo response: how words and rituals change the patient's brain, Patient Educ. Couns. 84 (2011) 413-419.

[49] M.A. Flaten, P.M. Aslaksen, P.S. Lyby, E. Bjørkedal, The relation of emotions to placebo responses, Philos. Trans. R. Soc. Lond. B: Biol. Sci. 366 (2011) 1818- 1827.

[50] F. Benedetti, M. Lanotte, L. Lopiano, L. Colloca, When words are painful: unraveling the mechanisms of the nocebo effect, Neuroscience 147 (2007) 260-271.

[51] D.L. Roter, J.A. Hall, Y. Aoki, Physician gender effects in medical communication: a meta-analytic review, J. Am. Med. Assoc. 288 (2002) 756-764.

[52] H. Sandhu, A. Adams, L. Singleton, D. Clark-Carter, J. Kidd, The impact of gender dyads on doctor-patient communication: a systematic review, Patient Educ. Couns. 76 (2009) 348-355.

[53] S. Willems, S. De Maesschalck, M. Deveugele, A. Derese, J. De Maeseneer, socioeconomic status of the patient and doctor-patient communication: does it make a difference? Patient Educ. Couns. 56 (2005) 139-146.

[54] M.S. Hagger, S. Orbell, A meta-analytic review of the common-sense model of illness representations, Psychol. Health 18 (2003) 141-184. 
Osch, M. van, Dulmen, S. van, Vliet, L. van, Bensing, J.M. Specifying the effects of physician's communication on patients' outcomes: a randomised controlled trial. Patient Education and Counseling: 2017, 100(8), 1482-1489

[55] L. Butalid, J.M. Bensing, P.F. Verhaak, Talking about psychosocial problems: an observational study on changes in doctor-patient communication in general practice between 1977 and 2008, Patient Educ. Couns. 94 (2013) 314-321.

[56] M. Neumann, F. Edelhäuser, D. Tauschel, M.R. Fischer, M. Wirtz, C. Woopen, A. Haramati, C. Scheffer, Empathy decline and its reasons: a systematic review of studies with medical students and residents, Acad. Med. 86 (2011) 996-1009.

[57] W. Levinson, R. Gorawara-Bhat, J. Lamb, A study of patient clues and physician responses in primary care and surgical settings, J Amer Med Assoc 284 (2000) 10211027.

[58] C. Zimmermann, L. Del Piccolo, A. Finset, Cues and concerns by patients in medical consultations: a literature review, Psychol. Bull. 133 (2007) 438-463.

[59] F. Dwamena, M. Holmes-Rovner, C.M. Gaulden, S. Jorgenson, G. Sadigh, A Sikorskii, S. Lewin, R.C. Smith, J. Coffey, A. Olomu, Interventions for providers to promote a patientcentred approach in clinical consultations, Cochrane Database Syst. Rev. 12 (2012) CD003267.

[60] J.K. Rao, L.A. Anderson, T.S. Inui, R.M. Frankel, Communication interventions make a difference in conversations between physicians and patients: a systematic review of the evidence, Med. Care 45 (2007) 340-349.

\section{FIGURES AND TABLES}

Fig.1. Profile of the study trial, showing numbers of participants from recruitment to randomisation to the four groups. N.B.: +Affect/+Expectation: warm, empathic GP with a positive outcome expectation,_affect/_expectation: cold, formal GP with an uncertain outcome expectation, +affect/_expectation: warm, empathic GP with an uncertain outcome expectation,_affect/+expectation: cold, formal GP with a positive outcome expectation. 
Osch, M. van, Dulmen, S. van, Vliet, L. van, Bensing, J.M. Specifying the effects of physician's/ communication on patients' outcomes: a randomised controlled trial. Patient Education and Counseling: 2017, 100(8), 1482-1489

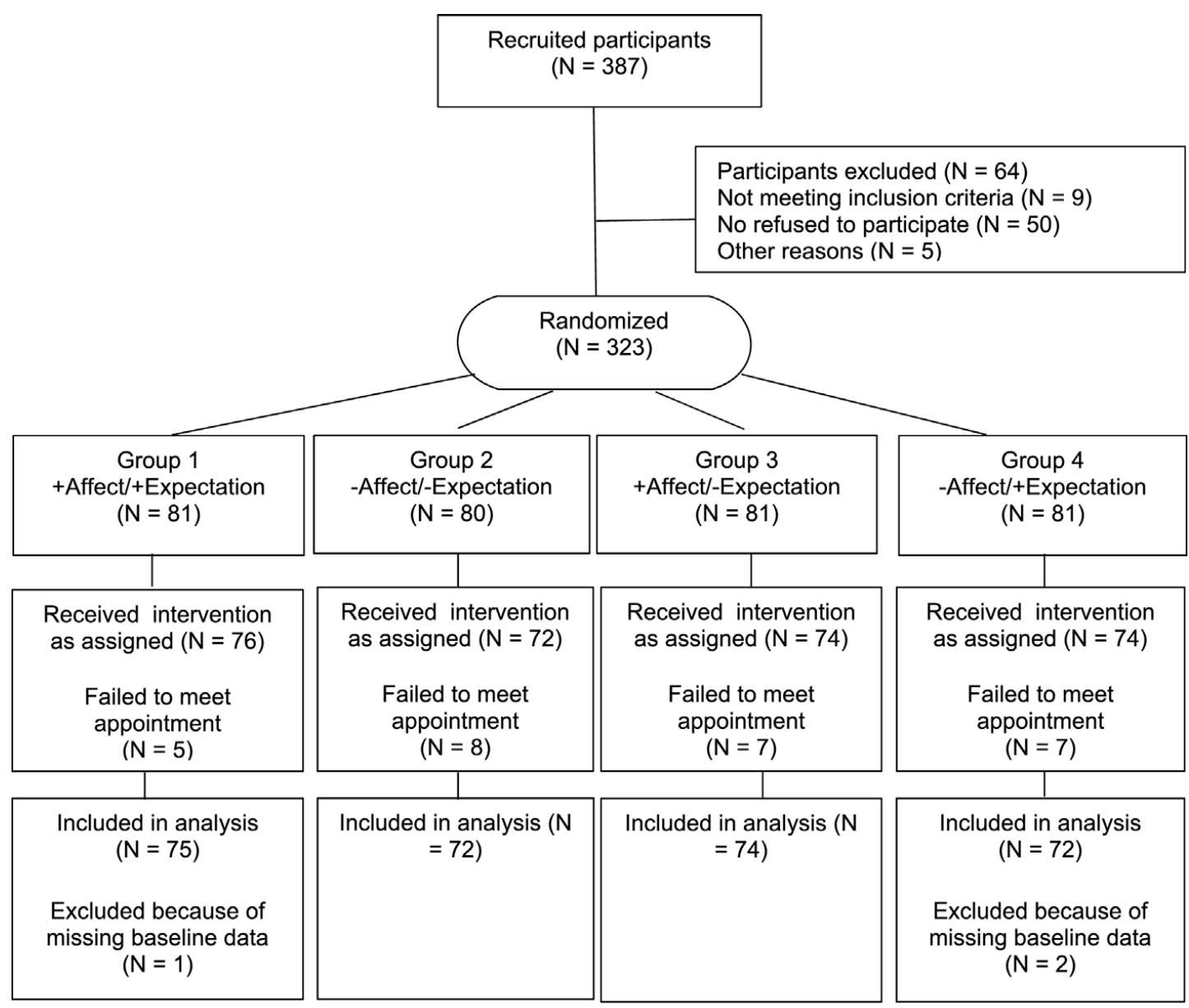

N.B.:

+Affect/+Expectation: warm, empathic GP with a positive outcome expectation -Affect/-Expectation: cold, formal GP with an uncertain outcome expectation +Affect/-Expectation: warm, empathic GP with an uncertain outcome expectation -Affect/+Expectation: cold, formal GP with a positive outcome expectation 
Osch, M. van, Dulmen, S. van, Vliet, L. van, Bensing, J.M. Specifying the effects of physician's communication on patients' outcomes: a randomised controlled trial. Patient Education and Counseling: 2017, 100(8), 1482-1489

Table 1. Background characteristics of participants.

\begin{tabular}{|c|c|c|c|c|c|c|}
\hline Variables & \begin{tabular}{|c|} 
Affect + \\
Expectations \\
+ \\
$N=75$ \\
\end{tabular} & \begin{tabular}{|c|} 
Affect - \\
Expectations \\
- \\
$N=72$ \\
\end{tabular} & \begin{tabular}{|c|} 
Affect + \\
Expectations \\
- \\
$N=74$ \\
\end{tabular} & \begin{tabular}{|c} 
Affect - \\
Expectati \\
ons + \\
$N=72$
\end{tabular} & $\begin{array}{c}\text { Total } \\
N=293\end{array}$ & \\
\hline & Mean (SD) & Mean (SD) & Mean (SD) & $\begin{array}{c}\text { Mean } \\
(\text { SD })\end{array}$ & $\begin{array}{c}\text { Mean } \\
(\text { SD })\end{array}$ & $(p)$ \\
\hline Age & $26.1(6.4)$ & $26.5(6.8)$ & $25.8(6.6)$ & $28.0(7.6)$ & $\begin{array}{l}26.6 \\
6.9)\end{array}$ & $\begin{array}{l}F(3289)=1.54 \\
p=0.20\end{array}$ \\
\hline Health status & $15.41(4.75)$ & $14.85(5.08)$ & $14.51(3.79)$ & $\begin{array}{l}14.56 \\
(4.62)\end{array}$ & $\begin{array}{l}14.83 \\
(4.57)\end{array}$ & $\begin{array}{l}F(3281)=0.57 \\
p=0.63\end{array}$ \\
\hline \multirow[t]{2}{*}{ Menstrual pain ${ }^{*}$} & $69.15(17.11)$ & $68.36(17.94)$ & $66.60(19.56)$ & $\begin{array}{l}69.31 \\
(20.85)\end{array}$ & $\begin{array}{l}68.34 \\
(18.83)\end{array}$ & $\begin{array}{l}F(3287)=0.32 \\
p=0.81\end{array}$ \\
\hline & $N(\%)$ & $N(\%)$ & $N(\%)$ & $N(\%)$ & $N(\%)$ & \\
\hline $\begin{array}{l}\text { Highest education }{ }^{\dagger} \\
\text { Lower } \\
\text { Middle } \\
\text { High }\end{array}$ & $\begin{array}{ll}- \\
34(45) \\
41(55)\end{array}$ & $\mid \begin{array}{ll}1 & (1) \\
27 & (38) \\
44 & (61)\end{array}$ & $\begin{array}{l}- \\
30(41) \\
44(59)\end{array}$ & 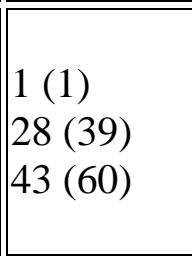 & \begin{tabular}{|l}
$2(1)$ \\
119 \\
$(40)$ \\
172 \\
$59)$
\end{tabular} & $\begin{array}{l}\chi^{2}(6)=3.00 \\
p=0.80\end{array}$ \\
\hline \begin{tabular}{|l|} 
Marital status \\
Married (incl. \\
registered partnership) \\
Never married \\
Other \\
(divorced/widowed/not \\
stated)
\end{tabular} & $\begin{array}{l}9(12) \\
65(87) \\
1(1)\end{array}$ & $\mid$\begin{tabular}{|l}
11 \\
$59(15)$ \\
$59(3)$
\end{tabular} & $\mid \begin{array}{l}5(7) \\
68(92) \\
1(1)\end{array}$ & $\mid$\begin{tabular}{||l}
$8(11)$ \\
$62(86)$ \\
$2(3)$
\end{tabular} & $\mid$\begin{tabular}{|l}
$33(11)$ \\
254 \\
$(87)$ \\
$6(2)$
\end{tabular} & $\begin{array}{l}\chi^{2}(6)=3.56 \\
p=0.74\end{array}$ \\
\hline \begin{tabular}{|l} 
Occupation $^{\ddagger}$ \\
Studying \\
Paid employment \\
Unemployed
\end{tabular} & $\begin{array}{l}38(51) \\
23(31) \\
14(18)\end{array}$ & $\mid \begin{array}{ll}39 & (54) \\
21 & (29) \\
12 & (17)\end{array}$ & $\begin{array}{l}38(51) \\
29(39) \\
7(10)\end{array}$ & $\mid$\begin{tabular}{|ll}
30 & $(42)$ \\
26 & $(36)$ \\
16 & $(22)$
\end{tabular} & $\mid$\begin{tabular}{|l||}
145 \\
$(49)$ \\
$99(34)$ \\
$49(17)$
\end{tabular} & $\begin{array}{l}\chi^{2}(6)=6.51 \\
p=0.37\end{array}$ \\
\hline \begin{tabular}{|l} 
Nationality \\
Dutch (incl. Western \\
immigrants) \\
Immigrant \\
\end{tabular} & $\begin{array}{l}59(79) \\
16(21)\end{array}$ & $\begin{array}{ll}61 & (85) \\
11 & (15)\end{array}$ & \begin{tabular}{|l}
$66(89)$ \\
$8(11)$
\end{tabular} & $\mid$\begin{tabular}{||l}
$54(75)$ \\
$18(25)$
\end{tabular} & $\left|\begin{array}{l}240 \\
(82) \\
53(18)\end{array}\right|$ & $\begin{array}{l}\chi^{2}(3)=5.88 \\
p=0.12\end{array}$ \\
\hline
\end{tabular}

* Menstrual pain in the last six months (0: no pain-100:unbearable pain).

$\dagger$ Lower education (<secondary school); middle (secondary school + vocational education); high (higher vocational education or University).

tUnemployed refers to looking for work, disabled, housewife, retired, or not stated). 
Osch, M. van, Dulmen, S. van, Vliet, L. van, Bensing, J.M. Specifying the effects of physician's communication on patients' outcomes: a randomised controlled trial. Patient Education and Counseling: 2017, 100(8), 1482-1489

Table 2. Pre and post-test measures between groups.

\begin{tabular}{|c|c|c|c|c|c|c|c|c|}
\hline \multirow[b]{2}{*}{ Out } & \multicolumn{2}{|c|}{$\begin{array}{c}\text { Group } 1 \\
+ \text { Affect/+Expectatio } \\
\text { n }\end{array}$} & \multicolumn{2}{|c|}{$\begin{array}{c}\text { Group } 2 \\
- \text { Affect/-Expectatio } \\
\text { n }\end{array}$} & \multicolumn{2}{|c|}{\begin{tabular}{|c|} 
Group 3 \\
+ Affect/-Expectatio \\
n
\end{tabular}} & \multicolumn{2}{|c|}{$\begin{array}{c}\text { Group } 4 \\
- \text { Affect/+Expectatio } \\
\text { n }\end{array}$} \\
\hline & $\begin{array}{c}\text { Pre } \\
\text { Mean } \\
(\text { SD) } \\
\end{array}$ & $\begin{array}{c}\text { Post } \\
\text { Mean } \\
\text { (SD) } \\
\end{array}$ & $\begin{array}{c}\text { Pre } \\
\text { Mean } \\
(\text { SD) } \\
\end{array}$ & $\begin{array}{l}\text { Post } \\
\text { Mean } \\
(\text { SD) } \\
\end{array}$ & $\begin{array}{c}\text { Pre } \\
\text { Mean } \\
(\text { SD) } \\
\end{array}$ & $\begin{array}{c}\text { Post } \\
\text { Mean } \\
(\text { SD) } \\
\end{array}$ & $\begin{array}{c}\text { Pre } \\
\text { Mean } \\
(\text { SD) } \\
\end{array}$ & $\begin{array}{l}\text { Post } \\
\text { Mean } \\
(\text { SD) } \\
\end{array}$ \\
\hline Anxiety & $\begin{array}{l}16.08 \\
(3.65)\end{array}$ & $\begin{array}{l}16.35 \\
(3.88)^{* \dagger \dagger}\end{array}$ & \begin{tabular}{|l|}
$\mathbf{1 7 . 8 5}$ \\
$(3.92)$ \\
\end{tabular} & $\begin{array}{l}25.31 \\
(7.35)^{* \S}\end{array}$ & \begin{tabular}{|l}
17.07 \\
$(3.84)$
\end{tabular} & $\begin{array}{l}21.08 \\
(6.52)^{\dagger \S}\end{array}$ & $\begin{array}{l}16.55 \\
(3.75)\end{array}$ & $\begin{array}{l}24.13 \\
(7.69)^{\ddagger}\end{array}$ \\
\hline \begin{tabular}{|l} 
Positive \\
mood \\
Negative \\
mood \\
\end{tabular} & $\begin{array}{l}26.74 \\
(3.38) \\
18.07 \\
(3.70) \\
\end{array}$ & $\begin{array}{l}26.82 \\
(3.90) \\
18.40 \\
(3.89)^{* *} \\
\end{array}$ & $\begin{array}{l}27.13 \\
(2.87) \\
\mathbf{1 9 . 1 0} \\
(\mathbf{3 . 3 9}) \\
\end{array}$ & \begin{tabular}{|l}
27.46 \\
$(3.44)$ \\
$\mathbf{2 1 . 5 3}$ \\
$(\mathbf{4 . 8 7})$
\end{tabular} & $\begin{array}{l}26.86 \\
(3.00) \\
18.81 \\
(4.51) \\
\end{array}$ & \begin{tabular}{|l}
26.89 \\
$(4.15)$ \\
19.11 \\
$(4.29)^{\S \Phi}$ \\
\end{tabular} & $\begin{array}{l}27.31 \\
(2.84) \\
\mathbf{1 8 . 9 7} \\
\mathbf{( 3 . 4 1 )} \\
\end{array}$ & 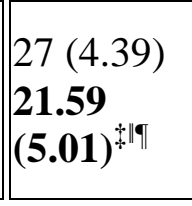 \\
\hline \begin{tabular}{|l|} 
Self- \\
efficacy \\
Outcome \\
expectancy
\end{tabular} & $\begin{array}{l}18(4.53) \\
15.93 \\
(3.16)\end{array}$ & $\begin{array}{l}\text { 21.89 } \\
(3.15)^{* \dagger \dagger} \\
18.96 \\
(2.97)^{* \dagger \dagger}\end{array}$ & \begin{tabular}{|l}
18.83 \\
$(4.75)$ \\
16.13 \\
$(3.39)$ \\
\end{tabular} & \begin{tabular}{|l}
15.89 \\
$(5.13)^{* \|}$ \\
12.49 \\
$(4.10)^{* \|}$
\end{tabular} & \begin{tabular}{|l}
19.93 \\
$(4.06)$ \\
17.08 \\
$(2.87)$ \\
\end{tabular} & \begin{tabular}{|l}
17.25 \\
$(4.39)^{\dagger}$ \\
13.49 \\
$(3.47)^{\dagger}$
\end{tabular} & $\begin{array}{l}18.92 \\
(5.04) \\
16.13 \\
(2.99) \\
\end{array}$ & \begin{tabular}{|l}
19.69 \\
$(4.09)^{\ddagger||}$ \\
16.18 \\
$(3.59)^{\ddagger||}$
\end{tabular} \\
\hline $\begin{array}{l}\text { Satisfactio } \\
\mathrm{n}\end{array}$ & & $\left.\begin{array}{l}7.11 \\
(1.68)\end{array}\right)^{* \dagger \dagger}$ & & $\mid \begin{array}{l}2.96 \\
(1.46)^{* \S}\end{array}$ & & 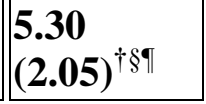 & & $\mid \begin{array}{l}3.38 \\
(1.76)\end{array}$ \\
\hline
\end{tabular}

N.B.: Bold pressed outcomes refer to significant differences within conditions $(p<0.05)$. Corresponding symbols refer to significant differences between conditions $(p<.05)$.

*Affect+/expectation+ with affect-/expectation-.

$\dagger$ Affect+/expectation+ with affect+/expectation-.

* Affect+/expectation+ with affect-/expectation+.

$\S$ Affect-/expectation- with affect+/expectation-.

"Affect-/expectation- with affect-/expectation+.

II Affect+/expectation- with affect-/expectation+.

Table 3. Distinct and combined effects of warm, empathic communication, and the raising of a positive outcome expectation, controlled for participants' pre-test measures, age and health status.

\begin{tabular}{||l||c|c|c|c|c|c|c|c||c||}
\hline \multicolumn{1}{|c|}{ Variables } & \multicolumn{3}{c|}{ Affect } & \multicolumn{3}{c||}{ Expectation } & \multicolumn{2}{c||}{ Affect ${ }^{*}$ expectation } \\
\hline \hline & $\boldsymbol{\beta}$ & $\mathbf{9 5 \%}$ CI & $\boldsymbol{p}$ & $\boldsymbol{\beta}$ & $\mathbf{9 5 \%}$ CI & $\boldsymbol{p}$ & $\boldsymbol{\beta}$ & $\mathbf{9 5 \%}$ CI & $\boldsymbol{p}$ \\
\hline \hline Anxiety & -0.25 & $-0.79--0.24$ & $<0.001$ & -0.10 & $-0.48-0.09$ & 0.17 & -0.21 & $-0.88--0.10$ & 0.02 \\
\hline \hline Positive mood & -0.05 & $-0.38-0.19$ & 0.51 & -0.11 & $-0.50-0.08$ & 0.15 & 0.06 & $-0.26-0.55$ & 0.50 \\
\hline \hline Negative mood & -0.23 & $-0.74-0.19$ & 0.001 & -0.02 & $-0.31-0.24$ & 0.80 & -0.02 & $-0.44-0.34$ & 0.80 \\
\hline Self-efficacy & 0.11 & $-0.05-0.51$ & 0.11 & 0.40 & $0.52-1.09$ & $<0.001$ & 0.12 & $-0.12-0.68$ & 0.17 \\
\hline \hline Outcome expectancy & 0.10 & $-0.06-0.47$ & 0.14 & 0.44 & $0.61-1.14$ & $<0.001$ & 0.20 & $0.10-0.85$ & 0.01 \\
\hline \hline Satisfaction & 0.49 & $0.73-1.21$ & $<0.001$ & 0.10 & $-0.05-0.44$ & 0.11 & 0.24 & $0.22-0.90$ & 0.001 \\
\hline \hline
\end{tabular}


Osch, M. van, Dulmen, S. van, Vliet, L. van, Bensing, J.M. Specifying the effects of physician's communication on patients' outcomes: a randomised controlled trial. Patient Education and Counseling: 2017, 100(8), 1482-1489

N.B.: Affect and Expectation were dummy coded. Affect refers to warm, empathic communication; expectation refers to the raising of a positive patient outcome. The standardised beta-coefficients $(\beta$ 's) illustrate the direction of the effect relative to the reference group.

* Satisfaction was not measured before video-viewing. 